\title{
Gerenciando Pessoas Utilizando Modelos Holísticos
}

\section{People's Management Using Holistic Models}

\author{
Cristina Mori Maciel* \\ Mestre em Administração pela UFPB. \\ Auxiliar de Auditoria de Contas Públicas do TCE/PB, João Pessoa/PB, Brasil. \\ Arlindo Fortunato da Silva \\ Especialista em Contabilidade e Auditoria Pública pela UFPB. \\ Auditor de Contas Públicas do TCE/PB, João Pessoa/PB, Brasil.
}

*Endereço: Avenida Índio Arabutam, 500, apto. 101, Cabo Branco, João Pessoa/PB, 58045-040.E-mail: cmaciel@tce.pb.gov.br 


\section{Resumo}

Este artigo propõe-se a estabelecer correlações entre modelos direcionados à gestão de pessoas nas organizações pós-modernas, através da descrição e da identificação de modelos encontrados na literatura, como também oferecer elementos para a reflexão sobre os conceitos advindos desses arquétipos. $\mathrm{O}$ ensaio se enquadra como estudo de natureza descritiva, cujas potencialidades relacionadas ao uso da abordagem holística na gestão de pessoas se realizam por intermédio da pesquisa bibliográfica e documental. A realização do artigo, com base na pesquisa bibliográfica e documental, resulta na possibilidade de vislumbrar ações que redundam em um exercício contínuo de cidadania corporativa, ações que contribuam para ampliar a consciência de respeito e colaboração entre as pessoas, de forma a beneficiar a todos os envolvidos. Como limitação do estudo pode-se mencionar a não possibilidade de generalizações dos conceitos e modelos para empresas de pequeno porte, visto não ter sido realizada pesquisa empírica para essa situação específica. Têm-se ainda, como contribuições do trabalho, a viabilidade de reunir diversos modelos encontrados em estudos anteriores, bem como apresentar os denominadores comuns existentes entre eles.

Palavras-chave: paradigma cartesiano; mecanicismo; mudança transformadora; perspectiva holística.

\section{Abstract}

This article considers to establish correlations between models directed to the management of people in the post-modern organizations, through the description and the identification of the models found in literature, as well as to offer elements for the reflection on the concepts based on these archetypes. The assay is fit as a study of descriptive nature, where the potentialities related to the use of the holistic approach in the management of people are carried out through documentary and bibliographical research. The accomplishment of the article on the basis of documentary and bibliographical research results in the possibility to glimpse actions that result in a continuous exercise of corporative citizenship, actions that contribute to extend the conscience of respect and contribution among people, in a way to benefit all the involved ones. As a limitation of the study it can be mentioned no possibility of generalizations of the concepts and models for small business companies; as it was not carried out empirical research for this specific situation. There is also, as a contribution of the work, the viability to congregate diverse models found in previous studies, as well as presenting the common denominators that exist between them.

Key words: cartesian paradigm; mechanicism; transformer change; holistic perspective. 
"A maior miséria da ciência é ter fundado uma neutralidade tão comprometedora e tão infeliz [...] ao lado de fantástica competência formal, que cresce em ritmo considerável, não tem nada a dizer sobre a felicidade do homem [...]. A ciência emerge como possivelmente monstruosa: a criatura humana que engole o homem. Sabemos demais como fazer guerra, como controlar o povo, como interferir na ecologia, mas sabemos quase nada, por vezes nada, de como sermos mais felizes".

Pedro Demo (1995, p. 260).

\section{INTRODUÇÃO}

Os últimos trinta anos do século 20 foram um campo fértil para filósofos e pensadores que estivessem dispostos a investigar eventos que mudaram radicalmente a história das civilizações ocidentais e os possíveis caminhos a serem seguidos pelas instituições ligadas aos governos e à sociedade civil.

Dentre as transformações que causam impactos mais significativos podem ser mencionados: a integração mundial; o desmoronamento das fronteiras; o crescimento de Organizações Não Governamentais (ONGs) ou organizações ligadas ao terceiro setor; as revoluções nos costumes; a poluição e a degradação ambiental; as alterações econômicas; a ampliação dos efeitos da globalização; o aumento da incerteza quanto ao futuro; e as diferentes possibilidades de escolha de estruturas e processos organizacionais.

De todos os temas elencados os que mais interessam são aqueles que envolvam modelos voltados para novas formas de gerenciamento de pessoas, que tentam incluir nos seus conceitos o equilíbrio entre a vida pessoal e a organizacional. Uma vez que o local de trabalho se tornou, nos últimos tempos, palco de conflitos, tais como: baixo comprometimento, turnover, rotatividade de pessoal, quebras de produtividade e absenteísmo.

Esses eventos podem ser explicados pelo uso contínuo de práticas e técnicas instrumentais oriundas do paradigma clássico ou mecanicista, focado no trabalho, na especialização, na autoridade, na hierarquia e no processo, que percebe a organização como máquina, com estruturas rígidas. Esse modelo tradicional não foi capaz de solucionar ou, pelo menos, mitigar a aparente divergência de interesses que movem os stakeholders e os funcionários; por isso é essencial para a sobrevivência e sucesso das organizações a inclusão de modelos referenciais 
ligados ao paradigma holístico, sistêmico ou orgânico, como tentativa de restabelecer a confiança e o respeito mútuo, abalados com a quebra do contrato psicológico, devido à reengenharia, ao downsizing e ao rightsizing a que foram submetidas as grandes organizações ao longo da década passada.

Feitas essas considerações preliminares, é oportuno informar que o presente artigo está distribuído em cinco partes.

O propósito da primeira parte é contextualizar e aprofundar os alicerces do paradigma científico, denominado clássico ou mecanicista, cuja aplicação a todas as áreas de conhecimento não deixou espaço para que as questões ligadas à intuição e à subjetividade fossem contempladas nas políticas e no cotidiano organizacional.

A segunda parte corresponde à incidência do paradigma holístico (pós-moderno), que propiciou abordagens mais voltadas para dimensões humanizadas nas Teorias Administrativas Contemporâneas.

A terceira parte reporta-se ao plano de recursos metodológicos utilizados para realizar a investigação.

A quarta parte aprofunda os conceitos ligados ao paradigma holístico, apresentando os modelos de gerenciamento que priorizam a humanização da organização, como também menciona exemplos de organizações que utilizam o construto.

A quinta parte apresenta as conclusões a que esse artigo permitiu chegar.

"Se outrora o fator decisivo era a terra e, mais tarde, o capital, visto como o conjunto de maquinaria e de bens instrumentais, hoje o fator decisivo é cada vez mais o próprio homem, isto é, a sua capacidade de conhecimento que se revela no saber científico, a sua capacidade de organização solidária, a sua capacidade de intuir e satisfazer a necessidade do outro". João Paulo II (como citado em Sirico \& Zieba, 2000, p. 120).

\section{O Modelo Clássico(1) e Suas Contradições}

A concepção do paradigma concentra-se em princípios como o reducionismo e a fragmentação na interpretação de fenômenos, pois se acreditava que seria possível interpretar as partes, para entender o todo. A falha no argumento é que 
ao reduzir-se a complexidade do objeto a ser investigado em elementos particularizados, formar-se-iam todos menores e não partes de um todo maior (Pereira, 2003).

Essa atitude reducionista encontra-se tão vinculada à nossa cultura que pode ser identificada como sendo o próprio método científico (Capra, 2000), de maneira que ainda hoje, após três séculos, é aplicada.

Essa fragmentação foi estendida a todas as ciências, de modo que, nos últimos tempos, o paradigma cartesiano-mecanicista, baseado na metáfora que entende ser o universo idêntico a um relógio ou a uma máquina de gigantescas proporções, está se desgastando. A crítica mais contundente ao modelo cartesiano é que ele conduziu a uma excessiva ênfase da fragmentação do modo de pensar e agir de toda uma sociedade, ocasionando até mesmo o tratamento de disciplinas do conhecimento como compartimentos estanques e separados (Pereira, 2003).

Havendo completo desmembramento entre o que se conhece no cotidiano e o que se estuda em sala de aula, percebe-se também uma incoerência considerável entre a retórica da gestão de pessoas e a realidade de suas práticas. Assim, com a reduzida correlação entre as diversas esferas de conhecimento, a ciência, pouco a pouco, foi formando especialistas, indivíduos com vasto saber a respeito de um assunto, e que desconhecem ou conhecem o mínimo do concernente a outras áreas de conhecimento afim.

Uma boa metáfora para explicar essa falta de sincronia entre as ciências foi criada por Alves (1996):

Tocar piano (como tocar qualquer instrumento) é extremamente complicado. O pianista tem de dominar uma serie de técnicas distintas [...] e coordená-las, para que a execução ocorra de forma integrada e equilibrada. Imagine um pianista que resolva especializar-se (grifo original) [...] na técnica dos trinados apenas. O que vai acontecer é que ele será capaz de fazer trinados como ninguém - só que ele não será capaz de executar nenhuma música. Cientistas são como pianistas que resolveram especializar-se numa técnica só (grifo original). Imagine as várias divisões da ciência - física, química, biologia, psicologia, sociologia - como técnicas especializadas. No início pensava-se que tais especializações produziriam, miraculosamente, uma sinfonia. Isto não ocorreu. $\mathrm{O}$ que ocorre, frequientemente, é que cada músico é surdo para o que os outros estão tocando. Físicos não entendem os sociólogos, que não sabem traduzir as afirmações dos biólogos, que por sua vez não compreendem a linguagem da economia, e assim por diante (p. 10). 
Enxerga-se com bastante nitidez que, devido à fragmentação e à especialização do conhecimento, os cursos universitários, mutatis mutandis, se assemelham à Torre de Babel (Weil, 2000), com os cientistas alçados à posição de mitos, respeitados e distantes do saber das pessoas comuns. O grande perigo de criarse esse tipo de estereótipo é que se permite a indução de comportamentos na sociedade e se inibe o pensamento, fazendo com que as pessoas não desenvolvam o poder de criticar.

Esse entendimento revela similaridade com o que foi explicitado por Freire (1990) que afirmou ser indispensável ao homem desenvolver uma mente crítica, a fim de poder defender-se dos perigos dos irracionalismos e dos encaminhamentos distorcidos da emoção, típicos dessa fase de transição pela qual passa o mundo.

Por sua vez, a visão newtoniana do mundo de causa-efeito está intimamente associada ao determinismo existente, porquanto, para cada fenômeno, existiria uma causa e um efeito determinados, e o futuro poderia ser previsto com certeza (Capra, 2002).

A aplicação do modelo clássico com sucesso no estudo dos fenômenos que envolvem as ciências naturais possibilitou a gradual universalização a todas as ciências, até mesmo às sociais, que passaram a utilizar-se dos métodos, das teorizações e das leis da regularidade. Essa abordagem concentrou-se na visão das pessoas como custos e o tratamento dado a elas como recursos (Davel \& Vergara, 2001). Com esse procedimento generalizado, os teóricos responsáveis pela evolução de conceitos, abordagens e aplicações direcionadas à gestão de pessoas esqueceram-se de que o comportamento humano apresenta diversos padrões de variabilidade. O comportamento humano é difícil de ser enquadrado, devido à capacidade humana de abstrair, inovar, criar e fantasiar a realidade. Enfim, o ser humano se destaca pela sua inteligência, afetividade e pela possibilidade de construir, destruir ou reconstruir tudo o que o cerca.

Portanto, por aproximadamente 300 anos, os teóricos e os cientistas perseguiram a objetividade como única forma válida de conhecimento. Contudo, ao longo do século 20, a ciência atualizou sua visão, com as descobertas dos efeitos da não linearidade nos fenômenos meteorológicos, sísmicos e nos organismos vivos (e. g. batimentos cardíacos); passou a considerar a aleatoriedade e a incerteza como marca maior do universo (Wheatley, 1999).

Essa perda definitiva da objetividade permitiu a inclusão nas organizações de conceitos ligados à subjetividade, à interioridade e à espiritualidade no ambiente de trabalho, como forma de capacitar os indivíduos a responder com rapidez e dinamismo às necessidades impostas por um mundo repleto de incertezas, constantemente submetido a mudanças (Pereira, 2003; Prahalad \& Hamel, 2005; Toffler, 1994). 
Assim, para Vergara e Branco (1993) os fundamentos de uma concepção holística do ser humano sempre estiveram presentes na história da humanidade, para verificar essa afirmativa bastaria revisitar as sabedorias milenares, passando pelos pensadores gregos e os místicos do oriente e do ocidente. $\mathrm{O}$ esforço atual é no sentido de resgatá-los, dentro de novo contexto, em que a vida humana é marcada por enorme complexidade. Isto é o que se propõe a seção a seguir.

"Não somos seres humanos tendo experiências espirituais; antes, somos seres espirituais tendo experiências humanas". Chardin (como citado em Boog, Marin, \& Wagner, n.d., p. 9).

\section{O Paradigma Holístico (2) (Pós-Moderno)}

Uma característica importante da sociedade contemporânea é a freqüência com que as transformações econômicas, sociais, políticas e culturais ocorrem; todas as mudanças se revestem de inquietações e de questionamentos perante as conquistas financeiras, em detrimento do meio ambiente e do imenso contingente humano que habita os países em desenvolvimento, já que podem ser consideradas inexpressivas as conquistas, em termos de qualidade de vida e de trabalho a que está submetida grande parte da população mundial.

A realidade circundante obriga o homem a lidar atualmente com conjunturas que não podem ser "explicadas pelo rigor do paradigma cartesiano, nem pela elegância dos modelos newtonianos" (Vergara \& Branco, 1993, p. 22), tampouco pela metodologia defendida por Bacon.

Quanto mais são realizadas investigações a fim de entender os problemas oriundos do modelo de mundialização vigente, mais três questões sobressaem-se:

- A desregulação econômica mundial, muito bem investigada por Castells (1999) que analisou as crises de credibilidade e de desvalorização de moedas de países localizados na região do Pacífico Asiático que provocaram recessão econômica na Indonésia, Coréia do Sul, Malásia, Tailândia, Hong Kong, Filipinas e Japão, cujos efeitos ainda são sentidos até o presente momento. Outra análise que pode ser feita a respeito da desregulação econômica mundial é a fragilidade do sistema financeiro de países em desenvolvimento perante ataques especulativos a suas moedas. Mostrando como bem empreenderam Vergara e Branco (1993) que "a economia há muito não respeita as fronteiras geográficas, muito menos os modelos econométricos" (p. 22). 
. O desregramento demográfico mundial que comporta um movimento imprevisível e de alto impacto nas localidades que recebem os imigrantes, visto que são necessários mais recursos destinados a programas sociais com moradia, assistência médico-hospitalar, escolas, transportes públicos; enfim, infra-estrutura.

- A crise ecológica se torna mais evidente, à medida que o movimento migratório se expande. O crescimento explosivo da população aumenta os níveis de desperdício e de poluição, ao passo que os recursos naturais dão mostras de esgotamento (Egri \& Pinfield, 1998).

Segundo Capra (2000), todos esses problemas devem ser entendidos em conjunto, como fazendo parte de um todo, isto é, "são problemas sistêmicos, o que significa que estão interligados e são interdependentes" (p. 23). Não podendo ser entendidos no âmbito da metodologia fragmentada, que é característica das disciplinas acadêmicas e dos organismos governamentais.

Daí a urgência de envolver acadêmicos, teóricos e profissionais responsáveis pela gestão das organizações em discussão mais abrangente que relacione diversas teorias que visam associar a idéia de que as instituições precisam desenvolver ações voltadas para a totalidade, tendo como suporte o holismo derivado do vocábulo grego hólos que significa todo, completo, inteiro.

A origem do holismo filosófico remonta à época de Heráclito (535-475 a.C), que viveu na Grécia Antiga, cuja ideologia ecoou no trabalho dos filósofos naturais e dos teólogos dos séculos 17 e 18 (e. g. von Linné, Emerson, Malthus e Thoreau) que escreveram a respeito da interconexão dos homens e da natureza na teia da vida (Wall, 1994). No entanto a visão holística sempre esteve presente na história da humanidade, podendo ser considerada como prática direcionada à busca de uma relação harmoniosa com a natureza, ao vegetarianismo das religiões orientais, à comunidade franciscana do século 13 e ao movimento Romântico Europeu que se desenvolveu nos séculos 17 e 18 (Egri \& Pinfield, 1998).

Foi no século passado, mais precisamente em 1926, que Jan Smuts desenvolveu o conceito de holismo organicista, como uma síntese ou uma união de partes que é tão compacta e intensa que é mais do que o total de suas partes, de forma que o todo e as partes, conseqüentemente, se influenciam e se determinam reciprocamente.

Ao contrário da perspectiva do paradigma social dominante, o modelo holístico tenta incorporar uma abordagem sistêmica (que abriga debaixo de seu guardachuva conceitos-chave como organizações autopoiéticas) e as leis de conservação e de entropia ${ }^{(3)}$ da termodinâmica (organizações auto-organizadoras ou dissipativas) ao contexto organizacional. 
Egri e Pinfield (1998) entendem que, ao visualizar as organizações como organismos, implicitamente está-se admitindo que sua sobrevivência continuada depende de um relacionamento interativo e interdependente, dela com o seu meio ambiente.

Coadunando com esse pensamento, Naviera (1998) define uma empresa autopoiética como organização que compreende residir em seus próprios recursos internos todo o potencial necessário para sua evolução, que busca permanentemente atualizar sua identidade, em congruência com as mudanças em seu ambiente externo e que faz uso da criatividade, da inovação e da experimentação para desenvolver e aprimorar seus estoques de conhecimento.

A segunda perspectiva encontra ressonância nos trabalhos de Lorenz, Prigogine, Emery e Trist. Destacam-se como características de organizações autoorganizadoras ou dissipativas os padrões de interação e conectividade entre as pessoas, de modo a permitir e a fomentar o surgimento espontâneo de sinergias catalisadoras de novas possibilidades, o reconhecimento da existência de contradições, de ambigüidade e de conflitos, com o intuito de utilizá-los em seu proveito, como fonte de aprendizado, criatividade e inovação (Naviera, 1998; Wheatley, 1999).

As descobertas científicas do início do século 20, que envolviam estudo das partículas atômicas, dos organismos vivos e das leis de conservação e de entropia da termodinâmica impuseram o fim definitivo do sonho de explicar a totalidade por meio de leis fundamentais invariantes e eternas (Navieira, 1998). As organizações que aplicarem modelos holísticos no seu gerenciamento diário só têm a ganhar, pois as desigualdades sociais e os desequilíbrios ecológicos aumentaram consideravelmente com as práticas comerciais que contemplam a maximização de retorno do capital somente para os acionistas e "socialização dos custos" para todos (Vergara \& Branco, 2001, p. 26; Egri \& Pinfield, 1998).

As formas encontradas pelas empresas para mitigar as disfunções do modelo de desenvolvimento adotado são variadas. Em países com condições de vida semelhantes ao Brasil, podem ser evidenciadas através de ações comprometidas com "a redução de impactos ambientais, com o apoio a grupos socialmente excluídos, com a erradicação das múltiplas causas de pobreza, tais como a ausência de educação" (Vergara \& Branco, 2001, p. 26).

Assim, diversas são as possibilidades de gerenciamento das empresas nos dias atuais, utilizando a abordagem sistêmica e as leis de conservação e de entropia da termodinâmica. Neste artigo, esses modelos serão examinados, com a apresentação de empresas, de porte variado, que se preocupam com o meio 
ambiente, com a qualidade de vida dos funcionários e em manterem-se longevas com a aplicação de conceitos inovadores.

“[...] As organizações estão aos poucos se tornando novas universidades no que tange à educação. Mas elas podem ir além em relação à plenitude: elas podem se transformar em novas catedrais para o terceiro milênio. Queremos dizer com isso que poderão devolver ao trabalho humano sua dignidade e à natureza seu caráter sagrado". Pierre Weil (como citado em Lemos, 2002, p. 489).

\section{Procedimentos Metodológicos}

O artigo tem como objetivo estabelecer correlações entre modelos direcionados à gestão de pessoas nas organizações pós-modernas, através da descrição e da identificação de modelos encontrados na literatura, assim como oferecer elementos para a reflexão sobre os conceitos apresentados.

O ensaio enquadra-se como um estudo de natureza descritiva, cujas fontes de informação e coleta de dados são livros, artigos publicados em periódicos científicos, eventos específicos das áreas de interesse da comunidade científica, como o Encontro da Associação Nacional dos Programas de Pós-Graduação em Administração (EnANPAD), os relatórios anuais das empresas e as revistas não acadêmicas, mas voltadas para o mercado.

A opção pela pesquisa bibliográfica e documental foi motivada por elas permitirem o acesso a uma importante fonte de dados e informações que não receberam tratamento analítico com a finalidade de buscar interpretações complementares (Godoy, 1995), além de a pesquisa documental possuir a seu favor a faculdade de não sofrer alterações nem modificações ao longo do tempo.

Assim, o sentido de investigar a existência de construtos e processos organizacionais voltados para um melhor aproveitamento dos recursos naturais, no desenvolvimento sustentável, em um gerenciamento de pessoas imbuído de ética, nas ações comprometidas com a responsabilidade social e com a cidadania corporativa, representa a necessidade de romper com um modelo empresarial e econômico apenas focalizado nos resultados econômicos (Rego \& Souto, 2004).

Coadjuvantemente com a realização da pesquisa documental que fundamentou os conceitos expostos, a quarta etapa do estudo consistiu na identificação das 
características relevantes que justificaram a especificidade de cada campo e sua inclusão nos modelos.

"Reconhecemos que cada um de nós faz parte dos problemas do mundo, e que também fazemos parte da solução". Petra Kelly (como citado em Castells, 2002, p. 141).

\section{Modelos Derivados do Construto}

As empresas, por possuírem grande poder de influenciar as políticas públicas, a comunidade que as cercam e conseguirem com maior agilidade adaptar-se às contingências ambientais, podem ser elementos-chave para liderar com as transformações necessárias para desenvolver a sociedade através de práticas de exercício da cidadania corporativa.

O artigo ressalta a importância de aumentar cada vez mais o número de empresas, governos e cidadãos engajados em causas sociais e humanitárias que contribuam para mitigar as desigualdades sociais. Cumpre enfatizar a responsabilidade do Estado, no sentido de fomentar políticas públicas direcionadas para o tema, bem como regulamentar por intermédio de legislação específica a possibilidade da empresa receber deduções tributárias via imposto de renda, como forma de estimular ações voltadas para a redução da emissão de gases poluentes na atmosfera, para a reutilização da água após tratamento em estações de efluentes, para o tratamento adequado dos esgotos industriais, antes de despejálos na natureza, programas que incentivem a disposição e o acondicionamento responsável de materiais tóxicos e não degradáveis. Pode o Estado delegar à iniciativa privada e à sociedade civil organizada a fiscalização desses serviços de interesse coletivo.

Movidos por essas preocupações, vários autores pesquisam a construção de modelos que englobam o paradigma holístico nas organizações, podendo ser mencionados: Geus (1998), Collins e Porras (1994, 1995), Den Dulk, Van Doorne-Huiskes e Schippers (1999 como citado em Rego \& Souto, 2004), Thompson, Beauvais e Lyness (1999), Vergara e Branco (2001), Catanante (2002), Martinelli (1997), Bell e Taylor (2004), Ashmos e Duchon (2000) e Kets de Vries (2001).

Da investigação realizada, emergiram seis modelos que serão examinados, de modo a destacar suas principais características e até mesmo seus 
denominadores comuns; por isso é importante frisar a similaridade dos modelos a serem apresentados nesta seção, visto que, à medida que é realizada a sua junção, os modelos podem mesclar-se, sofrer acréscimos ou retiradas de componentes.

Contudo a divisão explicitada em espécies tem o intuito de visualizar com maior facilidade as congruências dos modelos, visto que a sua concepção intrínseca é externalizar " [...] a operacionalização da emergência de um novo paradigma, centrado na ética, na responsabilidade social, na cidadania corporativa e no desenvolvimento sustentável" (Rego \& Souto, 2004, p. 32).

Empresas vivas são as que agem como comunidades humanas, conduzem suas ações com responsabilidade perante o meio ambiente e estimulam a visão de longo prazo, indo muito além dos interesses econômicos imediatos (Geus, 1998). Continuando nessa linha de raciocínio, Collins e Porras (1995) pesquisaram a longevidade de organizações; concluíram que as empresas que passaram do patamar de boas para excelentes o fizeram adotando processos de transformação evolutiva, de sorte que as empresas realmente visionárias são aquelas que fornecem as ferramentas, e não as soluções; objetivam mais do que lucros, isto é, possuem uma ideologia central; estimulam o progresso; buscam atingir metas audaciosas; cultivam figuras e artefatos mitológicos; testam teorias antes de aplicar o que der certo; investem em treinamento e capacitação de gerentes; e principalmente inovam permanentemente.

Em relação às características que servem para classificar uma empresa como viva, é a analogia mutatis mutandis com os organismos vivos, que buscam evoluir continuamente, a fim de melhor se adaptar às exigências do meio ambiente. Para Geus (1998): "provavelmente não importa muito se a empresa de fato está viva no sentido estritamente biológico da palavra ou se a 'empresa viva' é tão-somente uma metáfora útil (grifo original)" (p. xxiv).

O mesmo autor afirma que a empresa viva é orientada para a excelência, investe em processos de auto-renovação, busca incessantemente superar os próprios limites, diferencia-se para dar satisfação ao cliente, previne, identifica e soluciona problemas.

Segundo Pardini (2000), um dos grandes mistérios para os estudiosos das organizações tem sido decifrar as origens da longevidade das empresas vivas. Os resultados empíricos de pesquisas recentes constataram que a estabilidade administrativa e a perpetuidade da empresa podem advir de uma forte ideologia preservada e repassada continuamente pelos fundadores à nova geração de líderes executivos e da capacidade de sentir, aprender e se adaptar ao ambiente a sua volta (Collins \& Porras, 1994; Geus, 1998). 
Empresas amigas da família, na concepção de Den Dulk et al. (1999), são aquelas que demonstram preocupações com as relações familiares de seus colaboradores, oferecendo horários flexíveis, salas de amamentação, creches, bons programas para crianças e idosos, licenças-paternidade, serviços de guarda após o horário escolar, esquemas de interrupção de carreira e licença maternidade para as mulheres que adotam bebês (como citado em Rego e Souto, 2004, p. 32).

No entendimento de Thompson et al. (1999), os programas direcionados a incluir cuidados com a família propiciam o aumento da lealdade e do comprometimento com a organização, a redução do absenteísmo, do turnover e do conflito entre o trabalho e a família: toda essa política resulta para a empresa em aumento da produtividade.

Estudos de Grover e Crooker (1995) sugerem que programas voltados para incluir os familiares dos empregados influenciam o comprometimento afetivo e conseqüentemente os empregados demonstram baixa intenção de deixar a empresa em comparação com outras que não oferecem esses benefícios.

A extensão de benefícios aos familiares do empregado (e. g. programas de bolsa de estudos para os filhos, clube, creche e escola infantil) faz com que seja aditada a satisfação em pertencer aos quadros de empresas que estão preocupadas também com o bem-estar da família.

A concepção das empresas amigas da família tenta conciliar três dimensões aparentemente difíceis de harmonizar: satisfação com a profissão, realização no seio familiar e pessoal e desempenho organizacional. Talvez por esse motivo ainda seja adstrita às melhores empresas para trabalhar ou às maiores organizações.

A empresa humanizada, segundo Vergara e Branco (2001) é:

Aquela que, voltada para seus funcionários e/ou para o ambiente, agrega outros valores que não somente a maximização do retorno para os acionistas. Realiza ações que, no âmbito interno, promovem a melhoria na qualidade de vida e de trabalho, visam à construção de relações mais democráticas e justas, mitigam as desigualdades e diferenças de raça, sexo ou credo, além de contribuírem para o desenvolvimento das pessoas sob o aspecto físico, emocional, intelectual e espiritual. Ao focalizar o ambiente, essas ações buscam a eliminação de desequilíbrios ecológicos, a superação de injustiças sociais, o apoio a atividades comunitárias; enfim, o que se convencionou chamar de exercício da cidadania corporativa (p. 21).

A humanização é uma resposta inadiável à competitividade, ao consumismo e ao materialismo exarcebado e à destruição paulatina dos recursos naturais não 
renováveis. Assim, dos modelos de empresas humanizadas que atuam no contexto internacional, sobressaem nomes que já obtiveram sucesso no seu ramo de atuação, como o da fábrica inglesa de cosméticos Body Shop, da fabricante de roupas Levi Strauss e da rede varejista de brinquedos Toys "R"Us, sendo as duas últimas empresas norte-americanas.

No Brasil, as ações humanizantes são ainda incipientes, mas podem ser destacadas: C\&A, Natura, Bradesco, Banco Itaú, BankBoston, Coca Cola, Cerâmica Portobello, Bibi, Richter e Bottero (três fabricantes de calçados do Rio Grande do Sul) na categoria grande porte; no segmento médias e pequenas empresas tem-se o exemplo da Segatto Móveis de São Paulo (Vergara \& Branco, 2001). Além de Zanzini Móveis, Copagaz, Grazziotin, DPaschoal, Belgo-Mineira, Tupy Fundições e Bradesco. Todas as iniciativas das empresas humanizadas foram voltadas para a adesão a uma causa prioritária, no caso o foco de atuação escolhido foi a educação de crianças e jovens.

A humanização pode ser detectada até mesmo nas situações de desligamento da empresa, uma vez que, de acordo com Arruda (2002), há um conceito ainda em formação, o da demissão humanizada, em que se procura tratar de forma mais transparente e digna os demitidos, através da concessão de benefícios; como exemplos, podem ser citados prorrogação da assistência médica, bonificação em dinheiro, direito de continuar utilizando o carro da empresa por mais um período e auxílio para o pagamento do aluguel. Há também a possibilidade de o demitido poder tomar parte do projeto de recolocação profissional, via consultoria contratada especificamente para esse fim; atualmente o outplacement é estendido também a operários. Goulart (2004) mencionou a Merck Sharp \& Dohme do Brasil como exemplo de empresa que adotou a política de demissão humanizada.

Catanante (2002) especula.

A idéia de empresa-cidadã ou de empresa que valoriza a responsabilidade social e, portanto, age na comunidade com o intuito de propiciar um benefício, tem, na base, o conceito da espiritualidade no trabalho. A aplicação da espiritualidade no dia-a-dia está diretamente alinhada à prática integral da cidadania e da responsabilidade social - dentro e fora da empresa (p. 520).

O exercício do comportamento socialmente responsável, antes impensável, é uma das muitas conseqüências da evolução do estilo de gestão, que só pôde expandir-se porque as organizações ultrapassaram argumentos defendidos pelo Prêmio Nobel de Economia Milton Friedman que, há cerca de trinta anos, enunciou que a única e exclusiva responsabilidade social da empresa consistia em maximizar seus lucros (Nadas, 2002). Em pólo oposto, estão autores como Kotler (1978) e Drucker (1994), que vislumbraram novas responsabilidades e oportunidades para 
aqueles que abandonaram a postura tradicional filantrópica empresarial e se engajaram em assumir postura proativa.

Logo, a adoção de causas direcionadas ao exercício da cidadania e da responsabilidade social representa o propósito de contribuir para uma sociedade mais justa, incutindo no âmbito organizacional a consciência da necessidade premente de minimizar as precárias condições de vida de comunidades excluídas.

Similarmente à idéia expressa por Catanante (2002), incluída no presente artigo, Martinelli (1997) concebe a empresa-cidadã ou responsável socialmente como sendo aquela que opera sob concepção estratégica e compromissos éticos, cujos resultados influenciam a satisfação das expectativas e o respeito dos parceiros.

A empresa-cidadã ou responsável socialmente reveste-se de atributos similares à espiritualidade no ambiente de trabalho; assim, ela investe em ações que dão oportunidades aos funcionários e executivos de atuarem de forma prática e equilibrada (Catanante, 2002). São elas: a ABB no segmento de energia, a Samarco no ramo de mineração, a Mercedes-Benz no setor automotivo, o ABN no setor bancário. Por sua vez, é crescente o número de empresários conscientes da necessidade de se desenvolver um ambiente organizacional saudável; vai-se conseguindo produzir esse intento via promoção de "uma visão mais holística das empresas como centros comunitários, cujas ações podem ser vistas como interligadas, em termos morais e práticos, ao meio social e ambiental" (Bell \& Taylor, 2004, p. 65). Essas ações incluem: sentido de comunidade, alinhamento do indivíduo com os valores da organização, sentido de préstimo à comunidade, alegria no trabalho e oportunidades para a vida interior.

A espiritualidade no ambiente de trabalho é uma postura diante da vida, voltada para práticas de responsabilidade social, ambiental; enfim, com o bemestar coletivo. Catanante (2002) propõe que a prática da espiritualidade no local de trabalho como "todo valor pode ser desenvolvido, incentivado, promovido, e, portanto, vir a transformar-se em cultura organizacional e dentro de cada um" (p. 516).

A espiritualidade no ambiente de trabalho é uma idéia relativamente nova, mas certamente não é novidade em qualquer outro espaço da experiência humana, visto que, como sustentam Walsh e Vaughan (1995), o lado transcendental, religioso, estético e filosófico da vida é real e intrínseco à natureza humana.

Tal afirmativa pode ser constatada ao se observar as grandes tradições religiosas que, de alguma forma, encorajam seus seguidores a desenvolver uma vida contemplativa, em que a busca por significado e propósito, além do objetivo de viver em harmonia com os outros, é fundamental. Logo, a linguagem utilizada pelos que fazem parte do movimento em prol da espiritualidade no ambiente de trabalho 
está fundamentada na tradição da imagem religiosa, em especial daquelas que facilitam a inserção de práticas de culturas diversas, tais como as danças sufi e as filosofias orientais, adaptando-as ao contexto organizacional (Bell \& Taylor, 2004).

Ashmos e Duchon (2000) conceituam a espiritualidade no ambiente de trabalho como o reconhecimento por parte da organização de que seus empregados têm vida interior que necessita ser considerada. Além da vida interior, há dois outros componentes conformadores da espiritualidade no ambiente de trabalho: o significado do trabalho e o contexto de comunidade.

Os mencionados autores enfatizam que a espiritualidade no ambiente de trabalho não é religião, apesar de algumas pessoas expressarem suas crenças religiosas no trabalho. Partindo dessa premissa, há inúmeros exemplos de empresas nos Estados Unidos que procuraram aumentar o grau de consciência espiritual de seus empregados com a introdução deliberada de práticas espirituais e culturais. Como exemplos, podem mencionar-se a Xérox, que enviou um grupo de executivos graduados a retiro de nativos norte-americanos em um deserto do Novo México, e o Banco Mundial em Nova Iorque, que está envolvido em projeto que alinha os valores corporativos com os objetivos espirituais (Overell, 2001).

As experiências de espiritualidade no ambiente de trabalho, no Brasil, são ainda incipientes e reduzidas à construção de capelas, oferecidas como espaço reservado para reflexão dos colaboradores de qualquer religião, esses locais propícios para meditação são encontrados na SERASA (Cruz, 2004, p. 74) e na CTA(Moglia, 2004, p. 86). Contudo o conceito extrapola a simples manutenção de um recinto fechado; na verdade, perscruta o significado do trabalho em relação a um propósito maior.

Empresas autentizóticas são as que ajudam os colaboradores a estabelecer equilíbrio entre vida pessoal e organizacional. $\mathrm{O}$ vocábulo autentizótico é formado por um neologismo sugerido por Kets de Vries (2001), composto de duas palavras gregas: authenteekos e zoteekos.

A primeira palavra (authenteekos) significa que a organização é autêntica, merecedora de confiança. No local de trabalho, a autenticidade implica que a organização tem a obrigação de conectar qualidade para seus empregados na visão, missão, cultura e estrutura. Os líderes da organização comunicam-se de forma clara e convincente, revelando o significado de cada gesto pessoal. Estas são as organizações em que as pessoas encontram um senso de propósito, onde elas se sentem completas e vivas.

O segundo vocábulo (zoteekos) afiança que a organização é vital para as pessoas, fornecendo significado para suas vidas. No contexto organizacional, o termo zoteekos descreve o modo pelo qual as pessoas se sentem revigoradas pelo seu 
trabalho. As pessoas que trabalham nesses ambientes podem experimentar um senso de equilíbrio e completude.

São características relevantes encontradas em organizações autentizóticas: espírito de camaradagem, credibilidade do superior e oportunidades de aprendizagem e desenvolvimento pessoal. Assim, o intuito é tentar reunir elevado desempenho das organizações com a realização pessoal dos seus membros.

As empresas autentizóticas oferecem diversos tipos de benefícios a seus colaboradores, tais como participações nos lucros, planos de saúde, áreas de lazer, entre outros.

Não se pode negar que muitas empresas valorizarão ações voltadas para desenvolver o bem-estar dos empregados em troca de maior comprometimento, compromisso, desempenho e produtividade; outras desenvolverão os conceitos como estratégia de comunicação e marketing, para se promover e, conseqüentemente, aumentar seus resultados financeiros; no entanto o sucesso empresarial tem de vir acompanhado do retorno e reciprocidade também para o trabalhador sob a forma de benefícios.

Formação e treinamento, conciliação trabalho-família, participação nos lucros, licenças sabáticas, seguros-saúde, apoio médico, áreas para a prática desportiva, creches e apoio jurídico. Horários flexíveis de trabalho, empregos em tempo parcial e compartilhamento de postos de trabalho são também comuns. E, formal ou informalmente, muitas adotam políticas que evitam demissões (Rego \& Souto, 2004, p. 32).

Uns ou outros dos benefícios mencionados no parágrafo anterior podem ser encontrados nas empresas nacionais e internacionais, pois o gerenciamento de pessoas é hoje considerado uma forma de reduzir o absenteísmo, o turnover, as quebras de produtividade, entre outros problemas.

Além da preocupação em melhorar o tratamento e relacionamento com seus funcionários, há também, por parte das organizações, um movimento de ampliar para as comunidades circundantes as ações de responsabilidade social, geradas pelas fundações (e.g. Bradesco, Votorantim) e institutos (e.g. Souza Cruz, Avon), criados por diversas empresas que atuam em ramos importantes da economia com a finalidade de diminuir consideravelmente os problemas de depredação e invasão do patrimônio privado, de violência nas áreas adjacentes às empresas e de exclusão social.

A ampliação do papel da empresa em suas relações com o ambiente social é sustentada pela visão sistêmica, com a intenção de as primeiras assumirem papel consciente e ativo em suas relações com a sociedade abrangente (Fischer, 2002). 
As conclusões a respeito das características principais, reconhecidas e descritas neste artigo, serão apresentadas sob a forma de quadro, cuja intenção é sintetizar os modelos num único local e potenciar suas virtudes com destaque para a heterogeneidade e o hibridismo dos modelos que refletem as transformações do atual cenário organizacional.

\section{Quadro 1: Pluralidade de Modelos Organizacionais para Gerenciar Pessoas}

\begin{tabular}{|c|c|c|}
\hline Tipologias & Características principais & $\begin{array}{l}\text { Exemplos de empresas que } \\
\text { utilizam modelos holísticos }\end{array}$ \\
\hline Empresa viva & $\begin{array}{l}\text { Busca a evolução contínua com o fim de melhor se } \\
\text { adaptar às exigências do meio ambiente. } \\
\text { Pauta seus processos na auto-renovação, visando à } \\
\text { excelência. } \\
\text { Diferencia-se por dar satisfação ao cliente, através da } \\
\text { prevenção, identificação e solução de problemas. }\end{array}$ & \begin{tabular}{|lr} 
Tupy Fundições, & $3 \mathrm{M}$, \\
Construtora & Odebrecht, \\
Petrobrás, & Bradesco, \\
Votorantim, Gerdau &
\end{tabular} \\
\hline $\begin{array}{l}\text { Empresa amiga da } \\
\text { família }\end{array}$ & $\begin{array}{l}\text { Demonstra preocupações com as relações familiares de } \\
\text { seus colaboradores. } \\
\text { Oferece horários flexíveis, salas de amamentação, } \\
\text { creches, programas de desenvolvimento para crianças e } \\
\text { idosos, licenças-paternidade, serviços de guarda após o } \\
\text { horário escolar. } \\
\text { Faculta às funcionárias esquemas de interrupção de } \\
\text { carreira e licença por adoção. }\end{array}$ & $\begin{array}{l}\text { Landys+Gyr, Serra Grande, } \\
\text { DPaschoal e CTA }\end{array}$ \\
\hline Empresa humanizada & $\begin{array}{l}\text { Realiza ações que, no âmbito interno, promovem a } \\
\text { melhoria na qualidade de vida e de trabalho. } \\
\text { Visa à construção de relações mais democráticas e } \\
\text { justas. } \\
\text { Mitiga as desigualdades e diferenças de raça, sexo ou } \\
\text { credo. } \\
\text { Contribui para o desenvolvimento das pessoas sob o } \\
\text { aspecto físico, emocional, intelectual e espiritual. }\end{array}$ & $\begin{array}{l}\text { Zanzini Móveis, Copagaz, } \\
\text { Grazziotin, DPaschoal, Belgo- } \\
\text { Mineira, Tupy Fundições, } \\
\text { Bradesco }\end{array}$ \\
\hline \begin{tabular}{|l|}
$\begin{array}{l}\text { Empresa-cidadã ou } \\
\text { responsável } \\
\text { socialmente }\end{array}$ \\
\end{tabular} & $\begin{array}{l}\text { Estimula e valoriza o trabalho voluntário fora do } \\
\text { horário de trabalho junto à sociedade (e. g. associações } \\
\text { de bairro, entidades representativas, conselhos } \\
\text { comunitários, ONGs). } \\
\text { Prioriza ações e projetos capazes de aportar uma } \\
\text { contribuição mais efetiva para enfrentar a questão } \\
\text { social. } \\
\text { Adota postura de preservar o meio ambiente. } \\
\text { Uso racional dos recursos financeiros e mensuração } \\
\text { dos resultados dos projetos e/ou atividades que apóia. }\end{array}$ & $\begin{array}{l}\text { ABB, Samarco, Mercedes- } \\
\text { Benz, ABN Anro Bank, Avon, } \\
\text { Souza Cruz, Bradesco }\end{array}$ \\
\hline $\begin{array}{l}\text { Espiritualidade no } \\
\text { ambiente de trabalho }\end{array}$ & $\begin{array}{l}\text { Reconhece que o funcionário possui vida interior. } \\
\text { Encoraja o crescimento pessoal. } \\
\text { Estimula a busca de significado no trabalho. } \\
\text { Incentiva o senso de comunidade e respeito ao } \\
\text { semelhante, solidariedade, ética e bem-estar da } \\
\text { coletividade. }\end{array}$ & SERASA, CTA \\
\hline $\begin{array}{l}\text { Empresa } \\
\text { autentizótica }\end{array}$ & $\begin{array}{l}\text { Cria o sentimento de comunidade, apego e filiação nos } \\
\text { seus funcionários. } \\
\text { Desenvolve o senso de comprometimento e } \\
\text { afetividade. } \\
\text { Baseia suas práticas na confiança e no respeito mútuo. } \\
\text { Busca aumentar o senso de significado. }\end{array}$ & $\begin{array}{l}\text { Soeicom, Schahin Engenharia, } \\
\text { Grazziotin, WEG, Algar }\end{array}$ \\
\hline
\end{tabular}

Fonte: elaboração própria (2005). 
$\mathrm{O}$ estado da arte do gerenciamento estratégico de pessoas mostra que as empresas que mais se destacam no cenário nacional são aquelas que priorizam iniciativas voltadas para o desenvolvimento de ações de responsabilidade social (e. g. auditoria social, o balanço social) e ambiental (e. g. reciclagem de embalagens, metais pesados e outros insumos, redução no consumo de energia e água), conforme dados levantados em pesquisas realizadas por Tolfo e Piccini (1998), Moraes (1998), Ribeiro e Lisboa (1999), Oliva (2001), Silva e Freire (2001).

No entanto, pode-se inferir da análise do Quadro 1 que apesar dos avanços há ainda outros pontos que merecem ser mais bem trabalhados por autores interessados em investigar os construtos ainda em formação, no sentido de resgatar, convergir e discriminar resultados válidos.

Do exame das principais características citadas no Quadro 1, podem destacarse semelhanças, interseções ou denominadores comuns entre os modelos, visto que todos eles priorizam ações, projetos e atitudes direcionados à evolução, à inovação dos processos de gerenciamento de pessoas e à humanização do ambiente de trabalho. Reconhecem a importância de estimular aspectos relacionados à qualidade de vida e à qualidade de vida no trabalho. Ademais, estimulam a prática da responsabilidade social.

Como diferenças podem ser mencionadas as seguintes: oportunidades, programas de incentivos e/ou benefícios que determinadas empresas oferecem aos seus funcionários, o sentido de significado do trabalho e principalmente a forma de liderança.

Todas as condições mencionadas ao longo do texto não são necessariamente, suficientes para criar locais de trabalho cativantes, pois o senso de comunidade necessita de contextos capacitantes, arquitetura organizacional horizontalizada, cultura forte e liderança distribuída.

"Para nós, os seres humanos não são objetos; ou seja, controláveis por alguma mão invisível ou algum mecanismo, inatingível e auto-regulável, de ameaças. Para nós, o homem é um sujeito: um ser autodeterminado que é capaz de participar na transformação de seu mundo. Com a sua capacidade criadora, ele é capaz de transformar estreiteza em profundidade". Ramon Moreira Garcia (1980, p. 16). 


\section{Conclusões}

O uso de modelos inovadores baseados no paradigma holístico, para o gerenciamento de pessoas nas organizações, é um construto ainda em formação, que tem como desafio transpor o enfoque reducionista e excludente que, há muito, predomina na ciência, pela introdução no cotidiano organizacional de valores fundamentados na visão de totalidade, integração e na busca pelo equilíbrio entre vida pessoal e vida no trabalho.

Apesar de todas as dificuldades que se apresentam, observam-se variados modelos de gerenciar as pessoas nas organizações apresentadas nesse artigo: empresas vivas; empresas amigas da família; empresas humanizadas; empresascidadãs ou responsáveis socialmente; valorização da espiritualidade no trabalho e empresas autentizóticas. O paradigma holístico reveste-se de amplas possibilidades, não existindo modelo específico para ser seguido ou implementado.

Sendo papel da organização investigar, experimentar e analisar em qual modelo se encaixa o seu perfil, é possível adotar não apenas um construto, porém uma combinação deles ou criar um que melhor espelhe a sua realidade.

É bom chamar a atenção para o fato de que se deve afastar a idéia de que a abordagem holística é panacéia, e que ela por si só garantirá o sucesso tranqüilo das organizações, porque, conforme se explicita neste texto, os modelos são complementares e não simplesmente excludentes na sua totalidade.

Invariavelmente, as incertezas quanto ao futuro, às instabilidades econômicas e financeiras, ao desmoronamento de fronteiras, ao fenômeno da globalização continuarão a perturbar a vida das pessoas, e, conseqüentemente o funcionamento das organizações. No entanto existem diferentes possibilidades de escolha de estruturas e processos organizacionais que incluam a ética, a responsabilidade social, a cidadania corporativa e o desenvolvimento sustentável nas políticas gerenciais e empresariais.

Assim, a abordagem mais verossímil a ser adotada para a aplicação das diversas formas que o paradigma holístico pode revestir para gerenciar as organizações e em especial as pessoas é a perspectiva da realidade quântica, na qual as soluções constituem-se como sendo temporárias, específicas de um dado contexto e desenvolvidas por meio das relações entre as pessoas e as circunstâncias. Sem a pretensão de serem verdades incontestes e definitivas, já que a realidade muda de forma e significado, conforme a metáfora criada por Ralph Waldo Emerson: "Despertamos e vemo-nos numa escadaria; há degraus abaixo de nós, que parecemos ter subido, e há degraus acima de nós [...] que fogem ao alcance da vista" (como citado em Wheatley, 1999, p. 156). 


\title{
Artigo recebido em 19.11.2004. Aprovado em 26.01.2006.
}

\section{NotAs}

\begin{abstract}
${ }^{1}$ Alternam-se na literatura variadas denominações para o modelo clássico: reducionista, cartesianonewtoniano, mecanicista, positivista, ou ainda determinista.

${ }^{2}$ Podem ser encontrados na literatura os termos holísticos, sistêmicos, ecológicos e quânticos como sinônimos.

${ }^{3} \mathrm{O}$ processo entrópico é uma lei universal da natureza, em que todas as formas de organização se movem para a desorganização ou morte (Katz, D., \& Kahn, R. (1970). Psicologia social das organizações. São Paulo: Atlas.).
\end{abstract}

\section{ReferênCIAS Bibliográficas}

Alves, R. (1996).

Filosofia da ciência: uma introdução ao jogo e a suas regras. São Paulo: Ars Poética.

Arruda, A. (2002, dezembro 05). Empresas adotam demissão humanizada. Folha Online. Recuperado em 24 setembro, 2004, de http://www1.folha.uol.com.br/folha/ equilibrio/noticias/ult263u1948.shtml

Ashmos, D. P., \&

Duchon, D. (2000).

Spirituality at work: a conceptualization and measure. Journal of Management Inquiry, 9(2), 134-345.

Bell, E., \&

Taylor, S. (2004).

A exaltação do trabalho: o poder pastoral e a ética do trabalho na nova era. Revista de Administração de Empresas, 44(2), 64-78.
Boog, G. G.,

Marin, M. C., \&

Wagner, V. S. (n.d.).

Espiritualidade no trabalho. Recuperado em 31 julho, 2007, de http://www.guiarh.com.br/p55.htm

Capra, F. (2000).

A teia da vida: uma nova compreensão científica dos sistemas vivos (9a ed.). São Paulo: Cultrix.

Capra, F. (2002).

$O$ ponto da mutação (25a ed.). São Paulo: Cultrix.

Castells, M. (1999).

Fim do milênio. A era da informação: economia, sociedade e cultura (Vol. 3, 2a ed.). São Paulo: Paz e Terra.

Castells, M. (2002).

$O$ poder da identidade. A era da informação: economia, sociedade e cultura (Vol. 2, 3a ed.). São Paulo: Paz e Terra. 
Catanante, B. (2002).

Espiritualidade no trabalho. In G. G. Boog \& M. Boog (Coords.). Manual de gestão de pessoas e equipes: estratégias e tendências (Vol. 1). São Paulo: Gente.

Collins, J. C., \&

Porras, J. I. (1994).

Build to last successful habits of visionary companies. New York: Parper-Collins.

Collins, J. C., \&

Porras, J. I. (1995).

Feitas para durar: práticas bem sucedidas de empresas visionárias (8a ed.). Rio de Janeiro: Rocco.

\section{Cruz, P. (2004).}

Muito além do mero jogo de palavras. Valor Carreira, 2(2), 74-75.

Davel, E., \&

Vergara, S. C. (2001).

Gestão com pessoas e subjetividade. São Paulo: Atlas.

Demo, P. (1995).

Metodologia científica em ciências sociais (3a ed.). São Paulo: Atlas.

Drucker, P. F. (1994).

Administração de organizações sem fins lucrativos: princípios e práticas (5a ed.). São Paulo: Thomson Pioneira.

Egri, C. P., \&

Pinfield, L. T. (1998).

As organizações e a biosfera: ecologia e meio ambiente. In S. R. Clegg, C. Hardy, \& W. R. Nord (Orgs.). Handbook de estudos organizacionais. Modelos de análise e novas questões em estudos organizacionais (Vol. 1). São Paulo: Atlas.
Fischer, R. M. (2002).

A responsabilidade da cidadania organizacional. In M. T. L. Fleury (Coord.). As pessoas na organização (5a ed.). São Paulo: Gente.

Freire, P. (1990).

Educação e mudança (16a ed.). Rio de Janeiro: Paz e Terra.

Garcia, R. M. (1980).

A base de uma administração autodeterminada: o diagnóstico emancipador. Revista de Administração de Empresas, 20(2), 7-17.

Geus, A. de (1998).

A empresa viva: como as organizações podem aprender a prosperar e se perpetuar. Rio de Janeiro: Campus.

Godoy, A. S. (1995).

Pesquisa qualitativa: tipos fundamentais. Revista de Administração de Empresas, 35(3), 20-29.

Goulart, J. (2004).

Como fazer cortes sem abalar o moral. Valor Carreira, 2(2), 76-77.

Grover, S. L., \&

Crooker, K. J. (1995).

Who appreciates family-responsive human resource policies: the impact of family-friendly policies on the organizational attachment of parents and nonparents. Personnel Psychology, 48(2), 271-288.

Kets de Vries, M. F. R. (2001).

Creating authetizotic organizations: well-functioning individuals in vibrant companies. Human Relations, 1(54), 101-111. 
Kotler, P. (1978).

Marketing para as organizações que não visam o lucro. São Paulo: Atlas.

Lemos, J. L. (2002).

Cidadania empresarial: alavancando a responsabilidade social das empresas. In G. G. Boog \& M. Boog (Coords.). Manual de gestão de pessoas e equipes: estratégias e tendências (Vol. 1). São Paulo: Gente.

Martinelli, A. C. (1997).

Empresa-cidadã: uma visão inovadora para uma ação transformadora. In E. B. Ioschpe (Coord). Terceiro setor: desenvolvimento social sustentado. São Paulo: Paz e Terra.

Moglia, L. (2004).

Hora extra, só por espontânea vontade. Valor Carreira, 2(2), 86-87.

Moraes, W. F. A. de (1998, setembro). Administração estratégica e performance de grandes empresas brasileiras. Anais do Encontro Nacional da Associação Nacional de Pós-Graduação e Pesquisa em Administração, Foz do Iguaçu, PR, Brasil, 22.

Nadas, P. (2002).

Balanço social. In G. Boog \& M. Boog (Coords.). Manual de gestão de pessoas e equipes: estratégias e tendências (Vol. 1). São Paulo: Gente.

Navieira, R. B. (1998).

Caos e complexidade nas organizações. Revista de Administração Pública, 32(5), 69-80.

Oliva, E. C. de (2001, setembro). As ações de transformação organizacional que a Companhia Siderúrgica
Paulista - COSIPA vem desenvolvendo desde a sua privatização. Anais do Encontro Nacional da Associação Nacional de Pós-Graduação e Pesquisa em Administração, Campinas, SP, Brasil, 25.

Overell, S. (2001, September 20/21).

Spirituality in business. Recuperado em 31 julho, 2007, de http:// www.accessmylibrary.com/coms2/ summary_0286-10378261_ITM

Pardini, D. J. (2000, setembro).

A personificação da cultura corporativa como fator estratégico de longevidade e liderança: um estudo metodológico em três organizações brasileiras bem sucedidas. Anais do Encontro Nacional da Associação Nacional de Pós-Graduação e Pesquisa em Administração, Florianópolis, SC, Brasil, 24.

Pereira, M. F. (2003).

A gestão organizacional em busca do comportamento holístico. In M. T. Angeloni (Coord.). Organizações do conhecimento: infra-estrutura, pessoas e tecnologia. São Paulo: Saraiva.

Prahalad, C. K., \&

Hamel, G. (2005).

Competindo pelo futuro: estratégias inovadoras para obter o controle do seu setor e criar os mercados de amanhã (19a ed.). Rio de Janeiro: Campus.

Rego, A., \&

Souto, S. (2004).

Comprometimento organizacional em organizações autentizóticas: um estudo luso-brasileiro. Revista de Administração de Empresas, 44(3), 30-43. 
Ribeiro, M. S. de, \&

Lisboa, L. P. (1999, setembro).

Balanço social: instrumento de divulgação da interação da empresa com a sociedade. Anais do Encontro Nacional da Associação Nacional de Pós-Graduação e Pesquisa em Administração, Foz do Iguaçu, PR, Brasil, 23.

Silva, C. A. T., \&

Freire, F. S. de (2001, setembro).

Balanço social abrangente: um novo instrumento para a responsabilidade social das empresas. Anais do Encontro Nacional da Associação Nacional de Pós-Graduação e Pesquisa em Administração, Campinas, SP, Brasil, 25.

Sirico, R. A., \&

Zieba, M. (2000).

Agenda social: coleção de textos magisteriais. Pontifício Conselho 'Justiça e Paz'. Vaticano. Recuperado em 31 julho, 2007, de http:// www.thesocialagenda.org/pdfs/ portuguese.pdf

Toffler, A. (1994).

$O$ choque do futuro (5a ed.). Rio de Janeiro: Record.

Tolfo, S. R. da, \&

Piccini, V. C. (1998, setembro).

As melhores empresas para trabalhar no Brasil e a qualidade de vida no trabalho: disjunções entre a teoria e a prática. Anais do Encontro Nacional da Associação Nacional de PósGraduação e Pesquisa em Administração, Foz do Iguaçu, PR, Brasil, 22.
Thompson, C. A.,

Beauvais, L. L., \&

Lyness, K. S. (1999).

When work-family benefits are not enough: the influence of work-family culture on benefit utilization, organizational attachment, and workfamily conflict. Journal of Vocational Behavior, 54(3), 392-415.

Vergara, S. C., \&

Branco, P. D. (1993).

Em busca da visão de totalidade. Revista de Administração de Empresas, 33(6), 20-31.

Vergara, S. C., \&

Branco, P. D. (2001).

Empresa humanizada: a organização necessária e possível. Revista de Administração de Empresas, 41(2), 20-30.

Wall, D. (1994).

Green history: reader in environmental literature, philosophy and politics. New York: Routledge.

Walsh, R. N., \&

Vaughan, F. (1995).

Além do ego: dimensões transpessoais em psicologia. São Paulo: Pensamento.

Weil, P. (2000).

A normose informacional. Recuperado em 31 julho, 2007, de http:// www.ibict.br/cionline/include/ getdoc.php?id=590\&article $=$ $291 \&$ mode $=$ pdf

Wheatley, M. J. (1999).

Liderança e a nova ciência: aprendendo organização com um universo ordenado (2a ed.). São Paulo: Cultrix. 